\title{
CARACTERÍSTICAS FÍSICO-QUÍMICAS E ESTABILIDADE DO SUCO DE UMBU CO-CRISTALIZADO COM SACAROSE
}

\author{
IRANI PEREIRA DOS SANTOS * \\ LUCIANA ALBUQUERQUE CALDEIRA ROCHA** \\ ÉRIKA ENDO ALVES*** \\ MILTON NOBEL CANO-CHAUCA**** \\ MARYELLE CRISTINA SOUZA AGUIAR ${ }^{* * * * *}$
}

\begin{abstract}
Neste trabalho avaliou-se a encapsulação da polpa de umbu por co-cristalização com sacarose, determinando-se o efeito do $\mathrm{pH}$ da polpa adicionada sobre as propriedades físico-químicas do suco cocristalizado e sua estabilidade durante o armazenamento. O suco co-cristalizado apresentou alta solubilidade e baixa pegajosidade, situando-se na faixa em que se encontra a maioria dos pós alimentícios. Verificou-se que, de maneira geral, o suco de umbu co-cristalizado apresentou características físico-químicas que conferem boa estabilidade ao produto.
\end{abstract}

PALAVRAS-CHAVE: CO-CRISTALIZAÇÃO; UMBU; ATIVIDADE DE ÁGUA.

\footnotetext{
Engenheira Agrônoma, Mestre em Produção Vegetal no Semiárido, Universidade Estadual de Montes Claros (UNIMONTES), Campus Janaúba, MG (e-mail: iranipereirasantos@yahoo.com.br).

** Zootecnista, Mestre em Engenharia de Alimentos, Professora, Departamento de Ciências Agrárias, UNIMONTES, Campus Janaúba, MG (e-mail: luburq@yahoo.com.br).

*** Engenheira de Alimentos, Doutora em Ciência e Tecnologia de Alimentos, Professora, Instituto de Ciências Agrárias, Universidade Federal de Minas Gerais (UFMG), Campus Montes Claros, MG (e-mail: erikaendobr@yahoo.com.br).

**** Engenheiro de Alimentos, Pós-Doutor em Ciência e Tecnologia dos Alimentos, Professor do Instituto de Ciências Agrárias, UFMG, Campus Montes Claros, MG (e-mail: miltonc9@ hotmail.com).

***** Mestre em Produção Vegetal no Semiárido,

Doutoranda em Ciência e Tecnologia dos Alimentos, Universidade Federal de Santa Maria, Santa Maria RS (e-mail: maryelleaguiar@yahoo.com.br).
} 


\section{INTRODUÇÃO}

A co-cristalização, método de encapsulação, modifica a estrutura do cristal de sacarose de cristal puro para conglomerado, cuja estrutura providencia configuração porosa para a adição de outro ingrediente (BERISTAIN et al.,1994). Denomina-se o material externo de agente encapsulante, enquanto o ingrediente interno recebe a denominação de material ativo. Os carboidratos, entre eles a sacarose, são muito empregados como agentes encapsulantes de aromas devido sua capacidade de absorver voláteis do ambiente ou retê-los fortemente durante o processo de secagem (SHAHIDI e HAN,1993; NORI, 1996). O produto co-cristalizado apresenta baixa higroscopicidade e boas propriedades de fluidez e dispersão. Além disso, quando compostos sensíveis são aprisionados no interior dos aglomerados, ficam protegidos contra a oxidação (BERISTAIN et al.,1994; BHANDARI et al., 1998).

Para Astolfi-Filho et al. (2005), a técnica da co-cristalização baseia-se no princípio da microencapsulação e apresenta a vantagem de minimizar a degradação de vitaminas e a caramelização dos açúcares presentes nas frutas.

O processo se inicia com a concentração do xarope de sacarose de $70^{\circ}$ Brix até a solução se tornar supersaturada ( $\left.97^{\circ} \mathrm{Brix}\right)$, quando aquecida por alguns segundos. Adiciona-se à solução supersaturada o segundo ingrediente e promove-se agitação, sem aquecimento. De acordo com Awad e Chen (1993), a forma como se incorpora o segundo ingrediente assume fundamental importância e influencia as propriedades funcionais do co-cristalizado.

Chen, Veiga e Rizzuto (1988) citaram diversos produtos que podem ser encapsulados por co-cristalização com sacarose, tais como: sucos de frutas, óleos essenciais, chocolate, manteiga de amendoim e outros. Beristain et al. (1994) empregaram a co-cristalização para encapsular extrato de flores de hibisco (Hibiscus sabdarifa L.), resultando em produto com boa dispersibilidade, solubilidade, homogeneidade e fluidez, além da retenção de todo o aroma, sabor e cor característicos do extrato vegetal. Esses autores observaram importante efeito do $\mathrm{pH}$ do extrato sobre as propriedades do produto resultante.

Astolfi-Filho et al. (2005) estudaram o efeito das propriedades físicas (umidade, densidade aparente, ângulo de repouso e solubilidade) e a cinética de cristalização da sacarose, como agente encapsulante para suco de maracujá. Deladino et al. (2007) reportaram a encapsulação de extrato de erva mate (I. paraguariensis) e sais minerais em solução supersaturada de sacarose. O produto co-cristalizado mostrou comportamento típico de estrutura aglomerada com espaços vazios e cristais de sacarose com tamanho variando de 2 a $30 \mu \mathrm{m}$. Barbosa et al. (2009) realizaram a co-cristalização da sacarose em suco de açaí e obtiveram a caracterização do material cristalino formado por meio de difração de raio-X. Cheriegate (2012) avaliou amora-preta co-cristalizada com sacarose e verificou que a proporção 90:10 de sacarose:amora resultou em melhor estrutura do co-cristalizado.

Frutas regionais também podem ser beneficiadas pelo processo de co-cristalização, visto que sua elevada perecibilidade dificulta o transporte, o armazenamento e seu acesso a maior número de consumidores. Nesse contexto tem-se o umbu (Spondias tuberosa, Arruda Câmara), fruta típica do Semiárido nordestino e do norte de Minas Gerais, que apresenta grande importância socioeconômica para essas regiões e ampla aceitação pela população que a consome. Seu fruto, drupa com diâmetro entre 10 e $20 \mathrm{~g}$ e forma arredondada a ovalada, é constituído pela casca (22 \%), polpa (68 \%) e caroço (10\%). Apresenta superfície lisa, casca amarelo-esverdeada e polpa brancoesverdeada, mole e suculenta, quase aquosa quando madura e sabor agridoce (LIMA, ARAÚJO e ESPÍNDOLA, 2000).

Segundo Mattietto (2005), a polpa do umbu contém $89,4 \%$ de umidade, $4,93 \%$ de açúcares totais, $0,75 \%$ de proteínas, $0,30 \%$ de lipídios, $0,30 \%$ de fibras e $183,76 \mathrm{mg}$ de taninos $/ 100 \mathrm{~g}$, com teor de sólidos solúveis totais de 9,59 ${ }^{\circ}$ Brix e $\mathrm{pH}$ ácido de 2,75.

$\mathrm{Na}$ avaliação do teor de acidez da polpa in natura do umbu maduro, Ferreira, Cavalcanti- 
Mata e Braga (2000) encontraram 1,45 \% de ácido cítrico e teor de ácido ascórbico de 13,31 mg. $100 \mathrm{~g}^{-1}$. Considerando que o ácido ascórbico pode ser facilmente oxidado e degradado durante o armazenamento, a microencapsulação do suco de umbu com sacarose pode representar alternativa para melhorar a conservação de suas qualidades sensoriais e nutricionais, além de gerar produto seco e com boas propriedades de solubilidade, dispersão e fluidez.

Objetivou-se com este trabalho avaliar a influência do $\mathrm{pH}$ da polpa sobre as propriedades físico-químicas do suco de umbu co-cristalizado com sacarose e avaliar a estabilidade do produto durante o armazenamento.

\section{MATERIAL E MÉTODOS}

\subsection{LOCAL DO EXPERIMENTO}

O presente estudo foi desenvolvido no Laboratório de Tecnologia de Produtos de Origem Animal e Vegetal (TPAV), do Departamento de Ciências Agrárias, da Universidade Estadual de Montes Claros (UNIMONTES), campus de Janaúba, Minas Gerais.

\subsection{MATÉRIA-PRIMA}

Utilizou-se polpa de umbu congelada da marca Brasfrut, adquirida no comércio da cidade de Janaúba (MG). Os xaropes foram preparados com sacarose comercial (açúcar cristal marca Tryumpho) em água destilada.

\subsection{PREPARO DA POLPA}

A polpa, antes de ser co-cristalizada, foi filtrada e concentrada em evaporador rotativo (Fisatom - modelo 801), alcançando teor médio de sólidos solúveis totais de $16{ }^{\circ} \mathrm{Brix}$ e $\mathrm{pH}$ 2,79. $\mathrm{O}$ ajuste do $\mathrm{pH}$ da polpa antes da adição ao xarope ocorreu em pHmetro digital (pHmetro-3 MP, Tecnal), utilizando-se carbonato de cálcio (marca Synth, Diadema-SP), incorporado de forma a se obter polpas com pH 3,0; 3,5; 4,0 e 4,5.

\section{PREPARO DO CO-CRISTALIZADO}

Os xaropes de sacarose foram preparados em bateladas com cerca de $700 \mathrm{~g}$ de açúcar e concentração inicial de $70^{\circ}$ Brix em recipiente aberto de aço inoxidável e aquecidos até $150{ }^{\circ} \mathrm{C} \mathrm{em}$ chapa aquecedora (Fisatom, modelo $752 \mathrm{~A}$ ), com agitação mecânica até atingir $97^{\circ} \mathrm{Brix}$. A polpa de umbu com o pH ajustado foi adicionada ao xarope e agitada constantemente até a formação de material sólido particulado. Após a agitação, o material foi espalhado em bandejas forradas com papel manteiga e disposto em secador de bandejas com circulação de ar (Pardal - modelo Pe14) a $50^{\circ} \mathrm{C}$ por 24 horas. Após a desidratação, o co-cristalizado foi submetido à moagem e peneiramento para uniformizar sua granulometria. O produto, acondicionado em embalagens flexíveis metalizadas, foi armazenado em dessecadores contendo sílica gel até a realização das análises.

\subsection{CARACTERIZAÇÃO FÍSICO-QUÍMICA E AVALIAÇÃO DA ESTABILIDADE}

Para a caracterização do suco co-cristalizado foram efetuadas as seguintes determinações, em triplicata: atividade de água, $\mathrm{pH}$, sólidos solúveis totais (SST), umidade, higroscopicidade, solubilidade e stickiness. Avaliou-se a estabilidade do produto por meio de análise de cor durante 120 dias de armazenamento.

\subsection{ATIVIDADE DE ÁGUA (AW)}

As amostras do suco co-cristalizado foram transferidas para cápsulas de polietileno, com 
diâmetro interno de $3,8 \mathrm{~cm}$ para determinação da atividade de água em aparelho medidor do tipo AQUALAB (Series 3 Quik Start - Decagon Devices).

\section{$2.7 \mathrm{PH}$}

Para a análise de $\mathrm{pH}$ foram pesados $10 \mathrm{~g}$ das amostras do suco co-cristalizado em béquer, os quais foram diluídos em $100 \mathrm{~mL}$ de água destilada, homogeneizados e submetidos à leitura em pHmetro digital (pHmetro-3 MP, Tecnal), previamente calibrado com soluções tampões pH 4,0 e 7,0 (INSTITUTO ADOLFO LUTZ, 2008).

\subsection{SÓLIDOS SOLÚVEIS TOTAIS ('BRIX)}

Realizou-se a leitura dos sólidos solúveis totais ( ${ }^{\circ}$ Brix) das amostras em refratômetro digital (AR200 Digital Refractometer). Para o preparo da amostra, pesou-se $1 \mathrm{~g}$ do suco co-cristalizado em béquer, o qual foi diluído em $9 \mathrm{~g}$ de água destilada e homogeneizado, transferindo-se 1 a 2 gotas da solução obtida para a leitura no refratômetro (INSTITUTO ADOLFO LUTZ, 2008).

\subsection{UMIDADE}

Determinou-se a umidade das amostras por gravimetria em estufa a vácuo, segundo metodologia do Instituto Adolfo Lutz (2008). Cerca de $2 \mathrm{~g}$ de amostras do suco co-cristalizado foram pesados em cápsulas de alumínio e submetidos à estufa a $75^{\circ} \mathrm{C}$ até peso constante. Os resultados foram expressos em porcentagem.

\subsection{HIGROSCOPICIDADE}

Para determinar a higroscopicidade, $2 \mathrm{~g}$ de amostras do produto pesados em recipientes de papel alumínio foram colocados em dessecador contendo solução saturada de cloreto de potássio $(\mathrm{KCl}) \mathrm{com}$ atividade de água 0,85 sob temperatura de $25^{\circ} \mathrm{C}$. Para evitar o desenvolvimento de micro-organismos, devido condições de elevada umidade, foram adicionadas 2 gotas de formol à solução salina. As amostras foram pesadas em intervalos de 48 horas até atingir peso constante obtido em, aproximadamente, 20 dias. A higroscopicidade foi expressa como o conteúdo de água absorvida por $100 \mathrm{~g}$ de pó em base seca (g/100 g em b.s) conforme Barbosa (2010).

\subsection{SOLUBILIDADE}

A solubilidade das amostras foi determinada segundo o método descrito por Eastman e Moore (1984) com algumas modificações. Em $100 \mathrm{~mL}$ de $\mathrm{H}_{2} \mathrm{O}$ destilada adicionou-se $1 \mathrm{~g}$ do suco co-cristalizado, seguido de homogeneização em Mixer durante cinco minutos em alta velocidade. Essa solução foi colocada em tubos com tampa, centrifugados a $3000 \mathrm{rpm}$ durante dez minutos. Transferiu-se alíquota de $20 \mathrm{~mL}$ do sobrenadante para placas de Petri, previamente pesadas, e essas foram submetidas à secagem em estufa a vácuo (TE - 395/l TECNAL) à temperatura de $75^{\circ} \mathrm{C}$ por cinco horas. Calculou-se a solubilidade (\%) por diferença de peso.

\subsection{STICKINESS (PEGAJOSIDADE)}

Determinou-se o stickiness conforme Chen e Hosney (1995), com algumas modificações, em texturômetro (modelo TA XT Express marca Stable Micro Systems), instrumento que com a ajuda de software fornece diretamente a força adesiva (N). Utilizou-se probe (sonda) de 3,5 $\mathrm{mm}$ de diâmetro e $3,5 \mathrm{~mm}$ de altura e programou-se o texturômetro da seguinte forma: força de medida $(\mathrm{N})=$ compressão; Velocidade do pré-teste $=7,0 \mathrm{~mm} / \mathrm{s}$; velocidade do ensaio $=5,0 \mathrm{~mm} / \mathrm{s}$; velocidade 
do retorno $=10,0 \mathrm{~mm} / \mathrm{s}$; distância do ensaio $=68,0 \mathrm{~mm}$; ciclos do ensaio $=1$. Para essa análise, as amostras do suco co-cristalizado foram misturadas com glicerol na proporção de $5 \mathrm{~g} / 1,5 \mathrm{~mL}$ formando massa homogênea. Após a calibração do texturômetro e ajuste dos parâmetros, as massas foram colocadas no aparelho para realização das leituras.

\subsection{AVALIAÇÃO DA ESTABILIDADE}

Para verificar a estabilidade do suco co-cristalizado durante o armazenamento, as amostras foram submetidas à avaliação da cor nos tempos $0,20,40,60,80,100$ e 120 dias. Utilizou-se colorímetro modelo MiniScan EZ (Hunter Lab - EUA), nas seguintes condições: iluminante $D_{65}$ (luz do dia $6.500 \mathrm{~K}$ ), ângulo de $10^{\circ}$ para o observador e escala do sistema de cor "Cielab $L^{*} a^{*} b^{*}$, sendo a coordenada $L^{*}$ a luminosidade, a coordenada $a^{*}$ a intensidade do vermelho/verde e a coordenada $b^{*}$ a intensidade do amarelo/azul. Para essa análise, as amostras do suco co-cristalizado foram colocadas em placas de Petri e as leituras realizadas em triplicata. Para a avaliação da diferença de cor $(\Delta \mathrm{E})$ durante a estocagem adotou-se a equação 1 descrita por Langdon (1987) e Ozoglu e Bayindirh (2002):

$$
\left.\Delta \mathrm{E}=\left(\Delta L^{* 2}+\Delta a^{* 2}+\Delta b^{* 2}\right]^{1 / 2}\right)
$$

Em que:

$\Delta \mathrm{E}=$ diferença de cor;

$\Delta L^{*}=$ variação da luminosidade ou brilho (claro/escuro);

$\Delta a^{*}=$ variação na cromaticidade no eixo da cor verde (-) para vermelha (+);

$\Delta b^{*}=$ variação na cromaticidade no eixo da cor azul (-) para amarela (+).

\subsection{PLANEJAMENTO EXPERIMENTAL E TRATAMENTO ESTATÍSTICO}

Conduziu-se o experimento em delineamento com blocos casualizados (DBC), três repetições (blocos) e quatro tratamentos (polpa adicionada a $10 \%$ e pH ajustado para 3,0; 3,5; 4,0 e 4,5). Na análise da estabilidade utilizou-se o arranjo em parcelas subdivididas, tendo nas parcelas os tratamentos $(\mathrm{pH} 3,0 ; 3,5 ; 4,0$ e 4,5) e nas subparcelas os tempos de estocagem $(0,20$, $40,60,80,100$ e 120 dias). Os resultados foram submetidos à análise de variância (ANOVA) e ao estudo de regressão ao nível de $5 \%$ de probabilidade, utilizando-se o software estatístico SISVAR (FERREIRA, 2000).

\section{RESULTADOS E DISCUSSÃO}

\subsection{CARACTERÍSTICAS FÍSICO-QUÍMICAS}

Os resultados obtidos para as propriedades do suco de umbu co-cristalizado são apresentados nas Figuras 1 a 5 . Verifica-se que a maioria dos parâmetros avaliados sofreu influência do $\mathrm{pH}$ da polpa $(\mathrm{p}<0,05)$, exceto a solubilidade e o stickiness.

$\mathrm{O}$ suco produzido em $\mathrm{pH} 3,0$ proporcionou menor atividade de água $(0,40)$ e seu valor aumentou com a elevação do pH (Figura 1). Os valores obtidos situaram-se abaixo da faixa de crescimento microbiano, visto que geralmente alimentos com Aw menores que 0,6 são considerados microbiologicamente estáveis e a ocorrência de deteriorações é induzida por reações químicas ao invés de micro-organismos (QUEK, CHOK e SWEDLUND, 2007). Os baixos valores de atividade de água obtidos podem estar relacionados à capacidade da água de formar pontes de hidrogênio com os ácidos e se ligar aos grupos carbonilas da glicose e frutose da polpa, ficando imobilizada. 


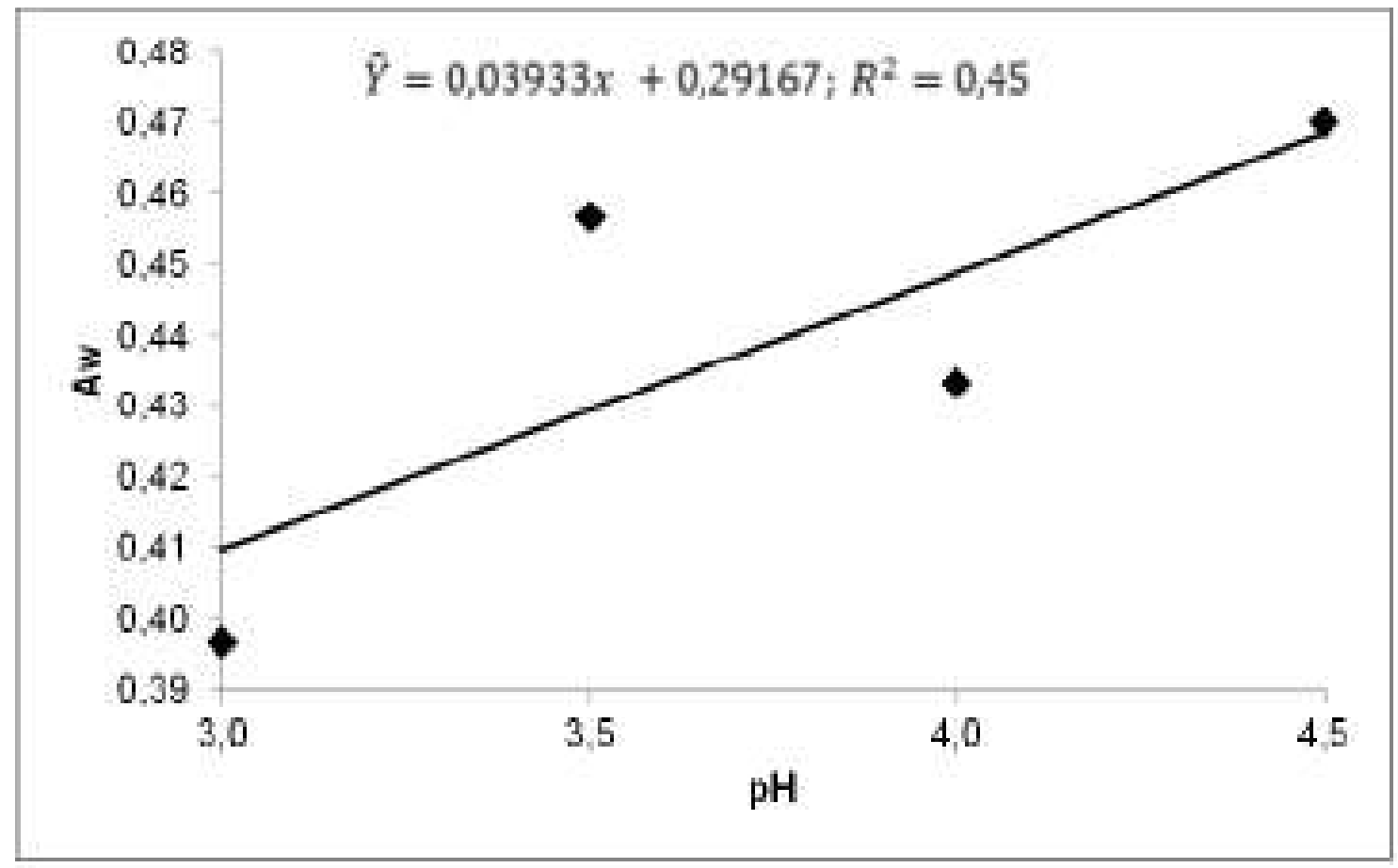

\section{FIGURA 1 - ATIVIDADE DE ÁGUA (AW) DO SUCO DE UMBU CO-CRISTALIZADO EM FUNÇÃO DO PH DA POLPA}

A atividade de água assume grande importância para os alimentos devido à sua influência sobre a vida útil do produto. Alta atividade de água indica mais água livre para as reações bioquímicas e, consequentemente, vida útil mais curta (ORDÓÑEZ et al., 2005).

Os resultados deste trabalho situaram-se abaixo dos relatados por Alexandre (2005), que encontrou atividade de água entre 0,85 e 0,86 em pitanga em pó produzida pelo processo de secagem em camada de espuma. Barbosa (2010) relatou valores de Aw na faixa de 0,26 a 0,33 para suco em pó de mistura de frutas obtido por spray drying e Dantas (2010) encontrou Aw de 0,23 para pó de abacaxi produzido pelo método foam-mat. Cheriegate (2012) obteve Aw entre 0,50 e 0,71 para amora-preta co-cristalizada com sacarose. Esses dados indicam que a co-cristalização gera produtos com baixa atividade de água e confere condições que aumentam sua vida-de-prateleira aos produtos.

Em relação ao $\mathrm{pH}$ do suco de umbu co-cristalizado, observou-se influência dos tratamentos $(\mathrm{p}<0,05)$. O suco oriundo de polpa com $\mathrm{pH} 3,0$ proporcionou o menor valor de $\mathrm{pH}$ (Figura 2), verificando-se aumento nos valores de $\mathrm{pH}$ conforme a elevação do $\mathrm{pH}$ da polpa de cada tratamento. O umbu é naturalmente ácido e sua polpa apresenta $\mathrm{pH} 2,75$ conforme Mattietto (2005). Segundo Astolfi-Filho (2003), a correção do pH da polpa antes da adição ao xarope torna-se necessária devido à cristalização da sacarose ser dificultada em pH muito ácido. Tal efeito é observado tanto na prática de fabricação de açúcar quanto na literatura estudada.

$\mathrm{O} \mathrm{pH}$, considerado um dos fatores determinantes para a estabilidade microbiológica dos alimentos, influencia sua microbiota (ARAÚJJ, 2004). Os valores de $\mathrm{pH}$ do suco de umbu co-cristalizado situaram-se entre 3,94 e 7,8, faixa em que pode ocorrer deterioração do alimento por fungos. Entretanto, o crescimento desses micro-organismos é dificultado pela baixa atividade de água, fato que pode tornar o produto estável quanto às alterações microbiológicas.

Souza et al. (2007), ao avaliarem pó de mix de polpas de frutas (umbu, seriguela e 
manga) obtido pelo processo de secagem em leito de jorro, encontraram $\mathrm{pH}$ ácido $(3,17$ a 3,21). Bastos et al. (2005) relataram pH de 4,29 para pó de manga produzido pelo método foam-mat. Já Soares et al. (2001) encontraram pH igual a 3,22 para pó de acerola obtido pelo método foam-mat.

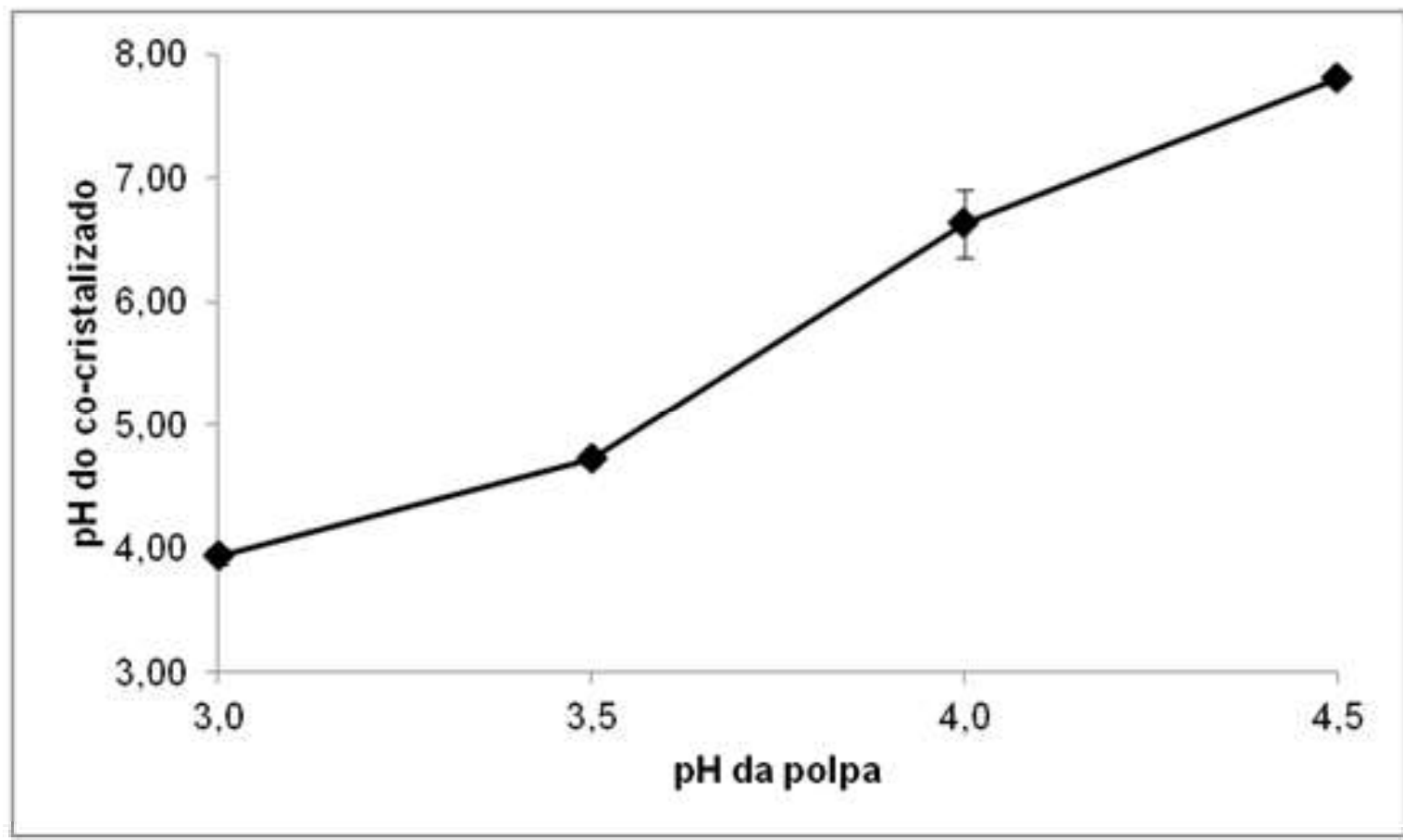

\section{FIGURA 2 - PH DO SUCO DE UMBU CO-CRISTALIZADO EM FUNÇÃO DO PH DA POLPA}

$\mathrm{O} \mathrm{pH}$ da polpa apresentou efeito significativo $(p<0,05)$ sobre os tratamentos quanto ao teor de sólidos solúveis totais do suco de umbu co-cristalizado. Observa-se pela Figura 3, que os sucos co-cristalizados produzidos com valores de $\mathrm{pH}$ mais elevados resultaram em maiores valores de sólidos solúveis totais ( $\left.{ }^{\circ} \mathrm{Brix}\right)$. Os valores de SST encontrados situaram-se na faixa de $91,67{ }^{\circ}$ Brix a $98,22^{\circ}$ Brix (Figura 3), os quais estão relacionados principalmente à grande quantidade de açúcar utilizada no preparo do xarope. Os tratamentos com pH 3,0 e 3,5 apresentaram menores conteúdos de SST, fato que pode estar associado com o ganho de umidade do produto que diminui os graus Brix (CANO-CHAUCA, 2000). Apesar da grande quantidade de açúcar utilizada, o gosto doce do produto final pode ser balanceado pelo gosto ácido característico da matéria-prima, visto que a polpa branqueada de umbu, segundo Oliveira (2006), apresenta acidez total titulável de 1,36 \% e pH de 2,95. Somente a análise sensorial da bebida (preparada a partir da dissolução do co-cristalizado em água) pode dar a certeza quanto à sua doçura e quanto à influência da quantidade de açúcar incorporado sobre a aceitação do produto. Essa avaliação, assim como a análise de intenção de compra, torna-se extremamente importante para o desenvolvimento do produto e faz parte dos estudos adicionais a serem realizados posteriormente.

Os valores de SST encontrados foram superiores aos observados por Soares et al. (2001) para pó de acerola (62,30 ${ }^{\circ}$ Brix) obtido pelo método foam-mat; por Cavalcanti Mata et al. (2005) para graviola liofilizada $\left(39,4^{\circ} \mathrm{Brix}\right)$ e por Costa et al. (2007) para pós de resíduo de abacaxi com casca e sem casca, $\left(60,38^{\circ}\right.$ Brix e $60,71^{\circ}$ Brix, respectivamente). Entretanto, mostraram-se próximos aos relatados por Dantas (2010) para pós de abacaxi (86,72 e $92,57^{\circ}$ Brix) obtidos pelo método foam-mat. 


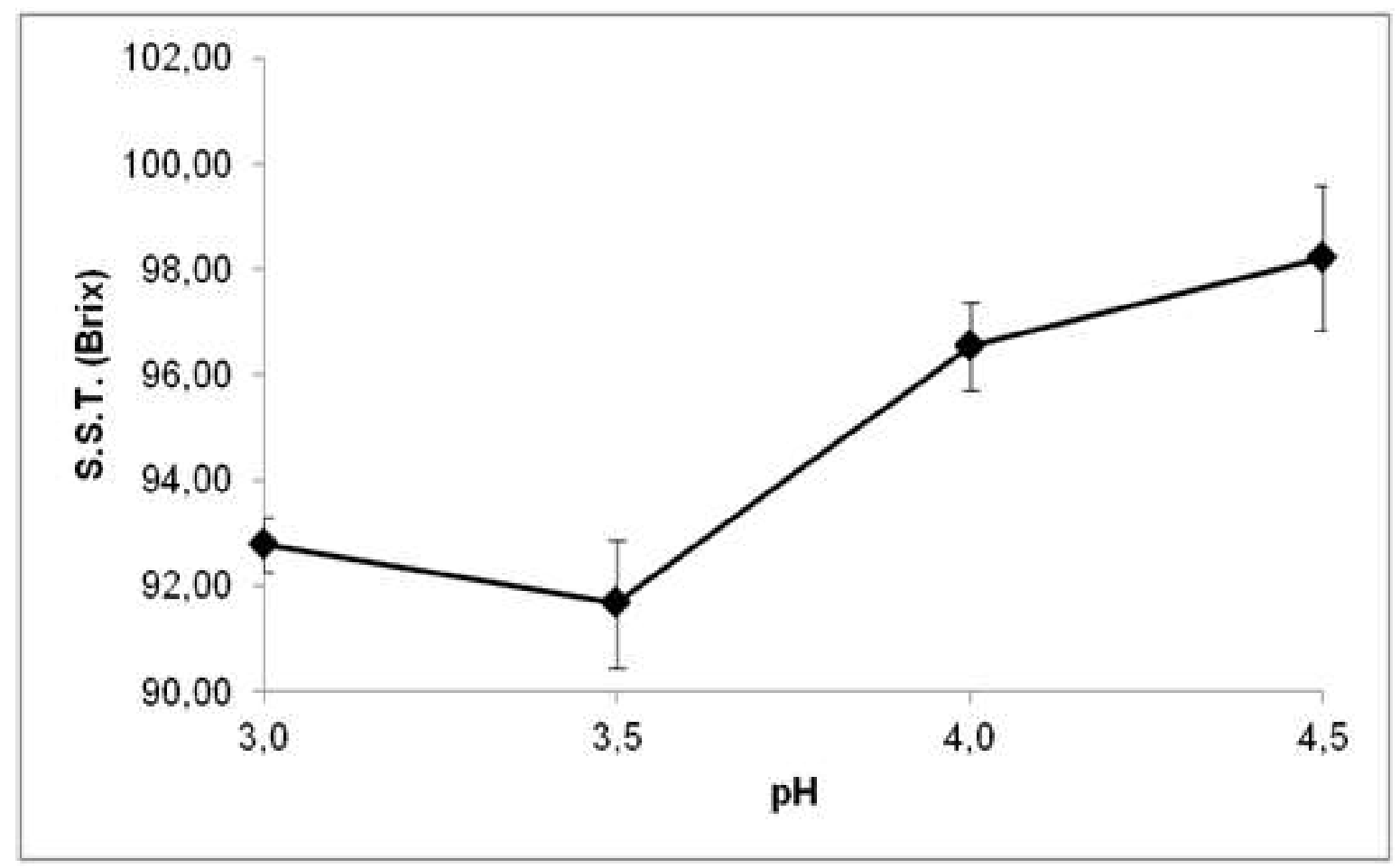

\section{FIGURA 3 - SÓLIDOS SOLÚVEIS TOTAIS (SST) DO SUCO DE UMBU CO-CRISTALIZADO EM FUNÇÃO DO PH DA POLPA}

Em relação ao teor de umidade do suco de umbu co-cristalizado, os resultados indicaram diferença significativa $(p<0,05)$ entre os tratamentos. As maiores umidades ocorreram na região de menor $\mathrm{pH}$ da polpa, enquanto os tratamentos com maior valor de $\mathrm{pH}$ da polpa proporcionaram menor conteúdo de umidade (Figura 4). Os valores médios da umidade do suco de umbu variaram entre 0,30 e $0,82 \%$ b.s. Esse resultado pode estar relacionado à adição do carbonato de cálcio que é antiumectante e antiaglutinante (ANVISA, 2011) ou ao fato do $\mathrm{pH}$ baixo favorecer a formação de glicose e frutose, açúcares que conseguem absorver mais água que a sacarose.

De acordo com Spoto (2006), alguns fungos são capazes de se desenvolverem em alimentos com baixo teor de umidade (12\%), enquanto bactérias e leveduras exigem níveis de umidade superiores a $30 \%$. Assim, a umidade do produto obtido não favorece o desenvolvimento de micro-organismos.

Os resultados apresentados por Astolfi-Filho et al. (2005) indicaram maiores umidades para co-cristalizados obtidos com maiores valores de $\mathrm{pH}$ de material encapsulado, comportamento distinto ao observado no presente trabalho. Ao estudarem a encapsulação do suco de maracujá por co-cristalização com sacarose em função do pH e da proporção de suco adicionado (10 \%) relataram umidade de $0,21 \%$ b.u. e $0,27 \%$ b.u. para suco com pH 3,5 e 4,5 respectivamente. Constataram, ainda, que para o co-cristalizado com suco de limão, a umidade encontrada oscilou entre $0,39 \%$ e $1,49 \%$ (base úmida).

Os valores de umidade encontrados para o suco co-cristalizado de umbu mostraram-se próximos aos mencionados por Tonon, Brabet e Hubinger (2008) para o suco de açaí em pó obtido por spray drying (faixa de 0,64 a 2,89 \% b.s.) e inferiores aos obtidos por Quek, Chok e Swedlund (2007), que relataram umidade entre 1,55 e 2,29 \% b.s para suco de melancia em pó obtido por spray drying. Esses dados demonstram que a co-cristalização pode gerar produto com umidade próxima ao do obtido pelo processo de spray drying, com a vantagem do método ser mais barato e viável para pequenos produtores. 


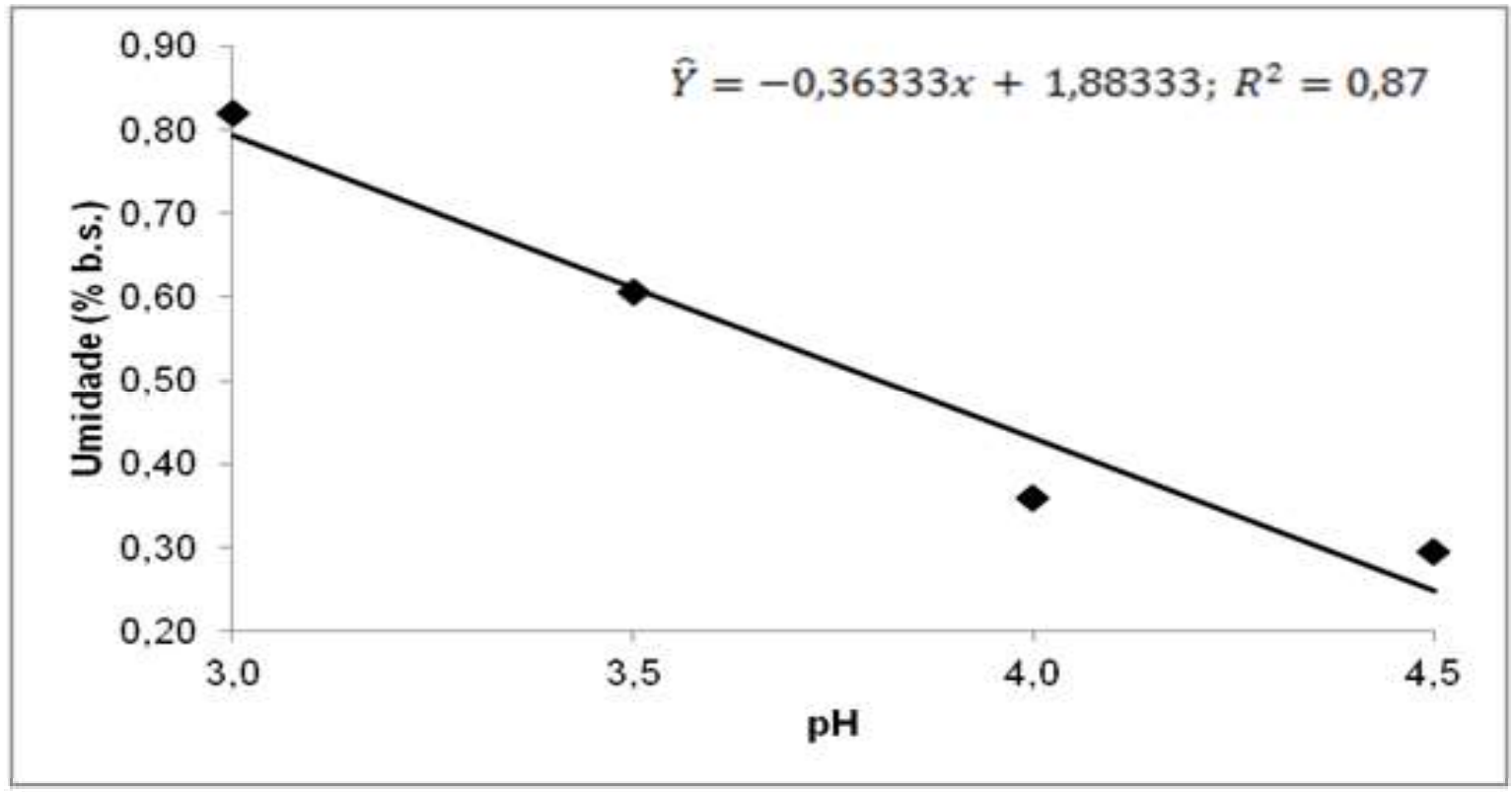

\section{FIGURA 4 - UMIDADE (\% B.S.) DO SUCO DE UMBU CO-CRISTALIZADO} EM FUNÇÃO DO PH DA POLPA

Quanto à higroscopicidade, o $\mathrm{pH}$ da polpa apresentou efeito significativo $(\mathrm{p}<0,05)$ sobre os valores de absorção de água ( $\mathrm{g}$ de H2O/100 g de sólidos) do suco de umbu co-cristalizado exposto à umidade relativa de $85 \%$ e temperatura de $30^{\circ} \mathrm{C}$. A maior absorção de água do produto $36,59 \mathrm{~g}$ $\left(\mathrm{H}_{2} \mathrm{O} / 100 \mathrm{~g}\right.$ de sólidos) ocorreu no suco produzido com pH 3,0 (Figura 5). As amostras com menor higroscopicidade corresponderam aos maiores valores de $\mathrm{pH}$, sendo que o material obtido com polpa de $\mathrm{pH} 4,5$ proporcionou o suco com a menor absorção de água $(3,94 \mathrm{~g} \mathrm{H} 2 \mathrm{O} / 100 \mathrm{~g}$ de sólidos). Esse suco foi considerado adequado, pois quanto menor a quantidade de água absorvida maior será a estabilidade do produto. A absorção de água de materiais alimentícios ricos em açúcares pode conduzir a mudanças nas propriedades de manuseio de fluxo e causar alterações físico-químicas e microbiológicas (ALMEIDA, 1995).

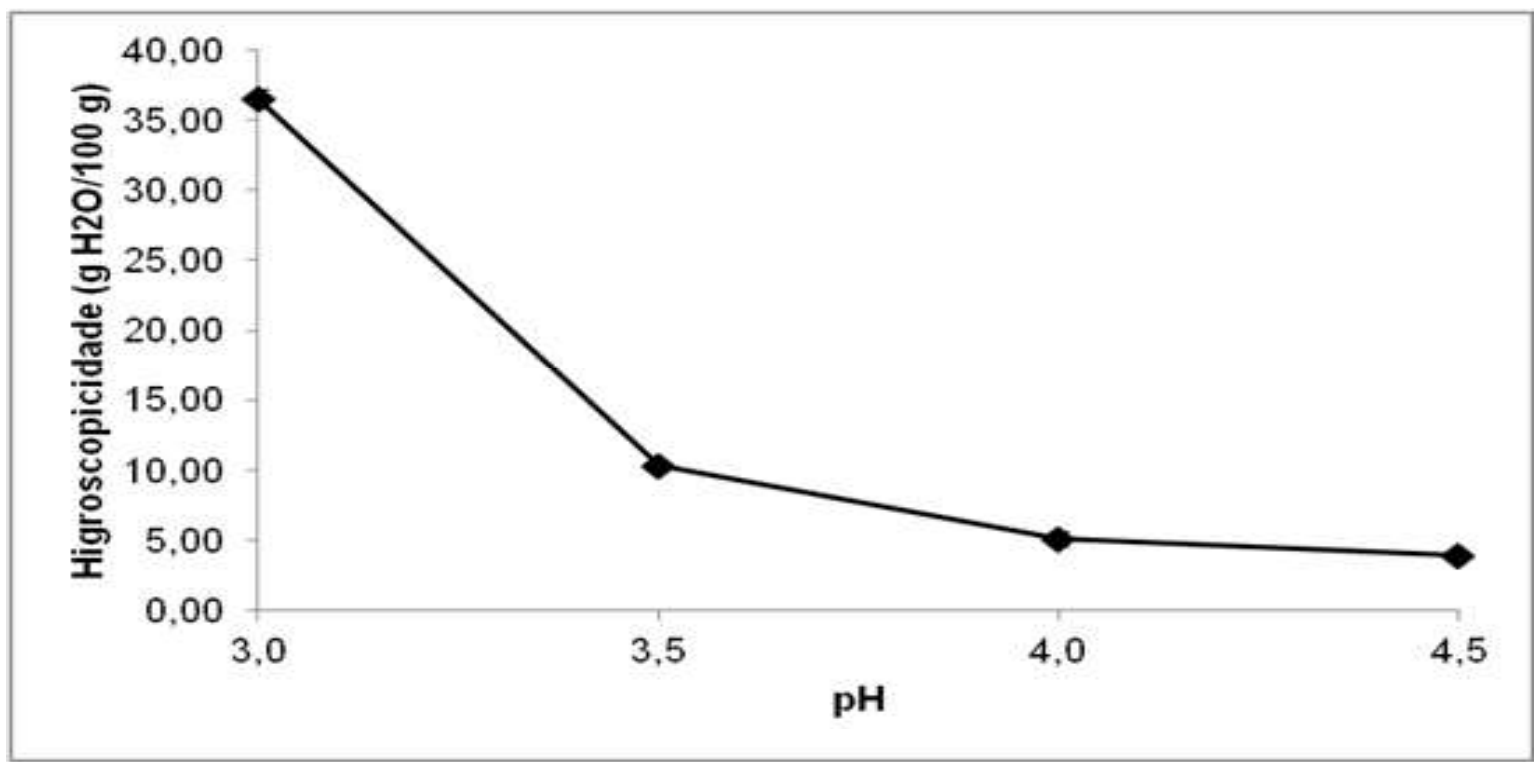

FIGURA 5 - HIGROSCOPICIDADE (G $\mathrm{H}_{2} \mathrm{O} / 100 \mathrm{G}$ DO PRODUTO) DO SUCO DE UMBU CO-CRISTALIZADO EM FUNÇÃO DO PH DA POLPA 
A menor higroscopicidade do suco de umbu co-cristalizado pode estar relacionada à maior concentração de carbonato de cálcio (antiumectante e antiaglutinante) nas polpas com pH mais elevado (ANVISA, 2011).

Provável explicação para o aumento da higroscopicidade nas amostras de suco de umbu cocristalizado refere-se à hidrólise da sacarose. Segundo Astolfi-Filho (2003), a sacarose pode sofrer hidrólise (inversão) durante a estocagem e produzir para cada molécula de sacarose quantidades equimolares de glicose e frutose. A inversão, controlada pela atividade de água e $\mathrm{pH}$, é favorecida em soluções levemente ácidas. Quando a atividade de água atinge 0,6, pequena quantidade de sacarose já pode ser dissolvida na superfície dos cristais e iniciar a reação de inversão. A frutose por ser mais higroscópica causa adsorção de maior quantidade de água que dissolverá mais sacarose e que será hidrolisada subsequentemente. Trata-se de fenômeno progressivo e que depois de iniciado é praticamente irreversível. Além disso, deve-se ressaltar que na avaliação da higroscopicidade, o tempo e a temperatura de armazenamento podem ter favorecido a hidrólise da sacarose, fato que pode justificar a diferença de comportamento observado entre essa análise e a avaliação da atividade de água (realizada com produto recém-processado, não estocado).

Cano-Chauca et al. (2005) reportaram ganhos de água na faixa de $20 \mathrm{~g}$ a $30 \mathrm{~g}$ de água/100 $g$ para suco de manga em pó obtido por spray drying. Silva et al. (2009), estudando a co-cristalizado de suco de açaí produzido em pH 3,5 e 4,0 constataram ganho de água entre $10 \mathrm{~g} \mathrm{e} 15 \mathrm{~g}(\mathrm{~g}$ água/100 g de produto) respectivamente. Barbosa (2010) relatou valores de absorção de água entre $20,85 \mathrm{~g}$ a $25,32 \mathrm{~g}$ (g água/100 g) em suco em pó de mistura de frutas obtido por spray drying.

A solubilidade do suco de umbu co-cristalizado não foi influenciada pelo $\mathrm{pH}$ da polpa $(p>0,05)$, atingindo média geral de $98 \%$. Beristain et al. (1994) também não observaram efeitos significativos de $\mathrm{pH}$ e porcentagem de extrato adicionado sobre a solubilidade do açúcar cocristalizado com concentrado de hibisco e consideraram que o produto apresentou excelentes propriedades de reconstituição.

Verificou-se alto grau de solubilidade em todos os tratamentos, comportamento que, segundo Awad e Chen (1993), pode ser explicado pelo fato das propriedades funcionais melhorarem com o encapsulamento dos materiais por co-cristalização. Esse comportamento pode estar relacionado também à própria solubilidade da sacarose (componente majoritário).

Resultados similares aos encontrados neste trabalho foram relatados por Santos et al. (2009) para suco de maracujá em pó produzido por co-cristalização (98,0 \%); por Barbosa (2010) para suco de mix de frutas obtido por spray-drying $(98,0 \%)$ e por Souza et al. (2007) para pó de mix de polpas de frutas elaborado pelo processo de secagem em leito de jorro (99,0\%). A solubilidade do produto obtido mostrou-se acima dos valores determinados por Moreira (2007) para pós de extrato microencapsulado de resíduo de acerola (90,97 \% a 96,92 \%), por Cano-Chauca et al. (2005) para pós de suco de manga obtidos por spray drying $(90,0 \%)$ e dos relatados por Abadio et al. (2004) para o suco de abacaxi em pó produzido por atomização (81,56 \%). Esses dados demonstram que os produtos co-cristalizados apresentam solubilidade comparável à obtida por outros métodos de encapsulamento, fato de grande importância para a reconstituição de produto em pó.

Em relação à propriedade de stickiness do suco de umbu co-cristalizado, não houve efeito significativo $(p>0,05)$ do $\mathrm{pH}$ da polpa (média geral de $4,10 \mathrm{~N}$ ).

O stickiness assume importância para produtos em pó, uma vez que influencia a aglomeração do produto. A água não foi utilizada para a formação da massa, pois sua adição pode afetar a temperatura de transição vítrea e, consequentemente, a pegajosidade (CANO-CHAUCA et al., 2005). Atribui-se o comportamento do stickiness à presença de alta concentração de açúcares com pequena massa molecular e de ácidos orgânicos, os quais apresentam baixa temperatura de transição vítrea $(\mathrm{Tg})$ e são pegajosos e termoplásticos na temperatura da câmara de secagem (BHANDARI e HARTEL, 2005).

Os dados do presente estudo corroboram os resultados encontrados por Cano-Chauca et al. (2005), que relataram valor médio de $0,53 \mathrm{Kg}-\mathrm{f}(5,2 \mathrm{~N})$ para o stickiness de pós de suco de manga 
obtidos por spray drying. Além disso, mostraram-se próximos aos verificados por Barbosa (2010), que encontrou valores de stickiness na faixa de 2,01 a 3,35 N para suco em pó de misturas de frutas. Os baixos valores de stickiness podem estar relacionados à presença do carbonato de cálcio.

\subsection{ANÁLISE DE ESTABILIDADE}

A estabilidade do suco de umbu co-cristalizado durante a estocagem foi avaliada quanto aos parâmetros de cor: luminosidade $\left(L^{*}\right)$, índice de vermelho $\left(a^{*}\right)$, índice de amarelo $\left(b^{*}\right)$ e diferença de cor $\left(\Delta \mathrm{E}^{*}\right)$ nos tempos $0,20,40,60,80,100$ e 120 dias de armazenamento.

A medida da cor constitui importante indicador de qualidade, visto que reflete a atratividade e a qualidade sensorial do produto. De acordo com a análise de variância, a avaliação instrumental da cor evidenciou influência dos tratamentos $(p<0,05)$ e do tempo de armazenamento $(p<0,05)$ para o parâmetro $L^{*}$. O estudo da regressão dos resultados mostrou que os modelos de $1^{\circ}$ grau apresentaram melhor ajuste para $\mathrm{pH}$ 4,0 e 4,5 e que nenhum modelo se ajustou aos demais $\mathrm{pH}$.

A luminosidade, coordenada que varia de 100 (branco) a 0 (negro), apresentou tendência à redução dos valores para a maioria dos tratamentos a partir dos 40 dias de estocagem. Na Figura 6 observa-se redução nos valores de $L^{*}$ para os sucos de umbu produzidos em $\mathrm{pH} 3,0 ; 3,5 \mathrm{e}$ 4,0 , os quais tenderam ao escurecimento. Entretanto, o aumento do $\mathrm{pH}$ incrementou os índices de luminosidade, fato que pode estar associado à maior estabilidade dos pigmentos (clorofila) predominantes na polpa de umbu utilizada nessa faixa de $\mathrm{pH}$.

Cheftel e Cheftel (1980), estudando o escurecimento dos alimentos, afirmaram que produtos com pH compreendido entre 2,5 e 3,5 são pobres em compostos aminados e sofrem reação de Maillard muito fraca. As reações responsáveis pelo escurecimento nesse caso envolvem a degradação do ácido ascórbico e/ou da frutose.

Quek et al. (2007) observaram redução da luminosidade de suco de melancia em pó obtido por spray drying devido ao escurecimento do pó causado pelo alto conteúdo de açúcares. Já Kha, Nguyen e Roach (2010), estudando os efeitos das condições de secagem por spray drying sobre as propriedades de cor de pós de gac fruit, encontraram aumento nos valores da luminosidade.

Sousa et al. (2008) observaram altos valores para a luminosidade de polpa de tomate em pó obtido por spray drying. Ramos et al. (2008) verificaram diminuição de luminosidade de fatias de abacaxi desidratado armazenado durante 75 dias em temperatura ambiente.

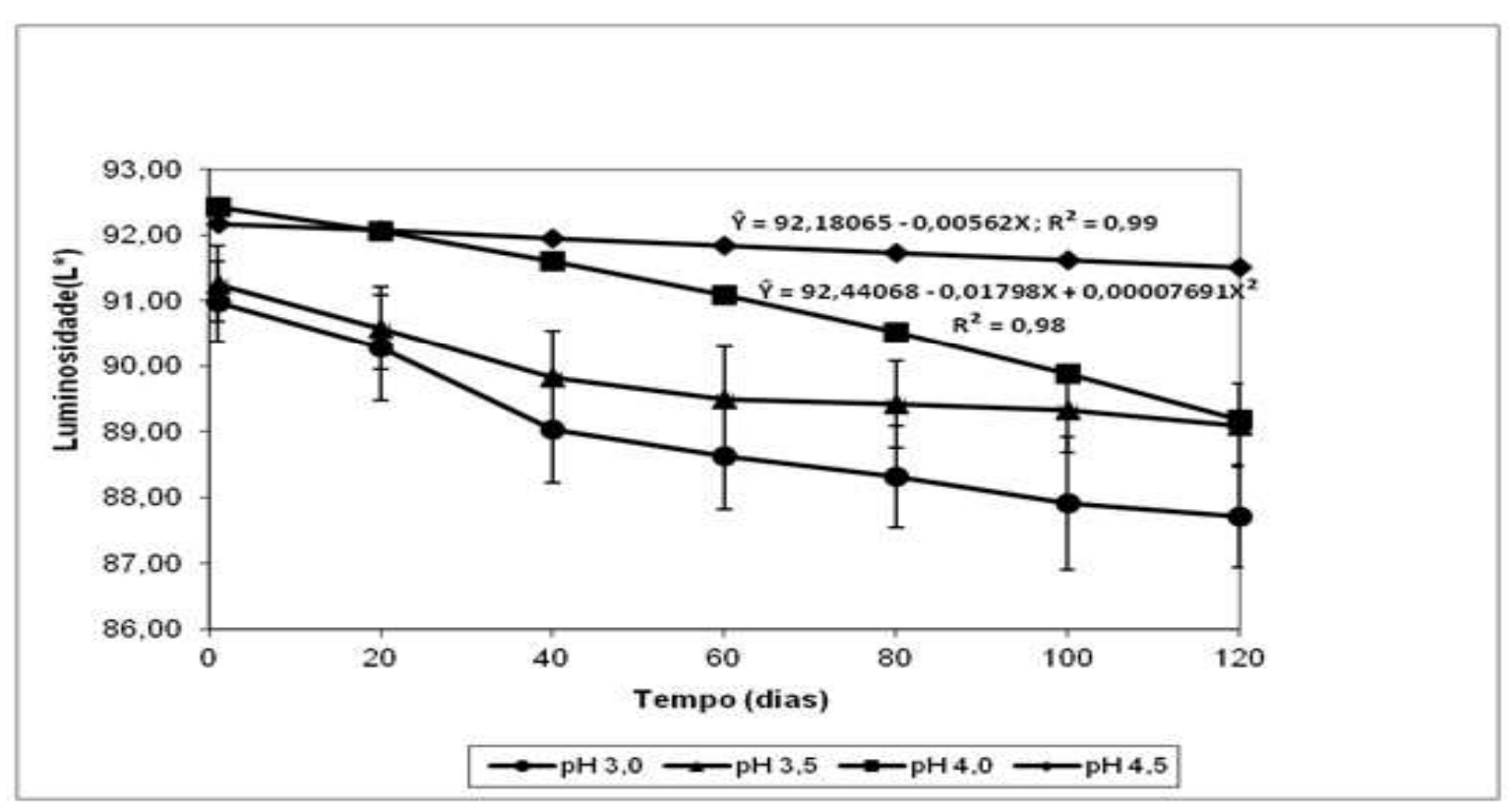

FIGURA 6 - LUMINOSIDADE (L*) DO SUCO DE UMBU CO-CRISTALIZADO DURANTE O ARMAZENAMENTO 
Em relação à coordenada $a^{*}$, os resultados obtidos pela análise de variância indicaram que houve influência do $\mathrm{pH}$ da polpa e do tempo de estocagem $(\mathrm{p}<0,05)$. O parâmetro $a^{*}$ que no croma indica a variação de verde $\left(-a^{*}\right)$ a vermelho $\left(+a^{*}\right)$ tendeu para diminuição do verde (Figura 7$)$. Valores positivos nas menores faixas de $\mathrm{pH}$ podem estar associados à degradação de pigmentos, principalmente da clorofila responsável pela coloração verde da polpa de umbu. Os valores positivos para $a^{*}$ indicam que o pó obtido apresenta tonalidade levemente avermelhada, provavelmente devido aos carotenoides totais da polpa.

A decomposição das clorofilas sofre influência do $\mathrm{pH}$ dos tecidos. $\mathrm{O} \mathrm{pH}$ básico $(9,0)$ torna a clorofila mais estável ao calor, quando comparada ao ácido $(3,0)$. Os íons positivos minimizam a permeabilidade da membrana, que entra em equilíbrio com as cargas negativas diminuindo, dessa forma, a degradação das clorofilas (VON ELBE, 2000). Essa instabilidade da molécula pode alterar a sua cor, o valor comercial e sua qualidade nutritiva, causando também impressão negativa do produto (SHOEFS, 2002).

$\mathrm{Em} \mathrm{pH} \mathrm{4,5}$ verificou-se melhor estabilidade da coordenada $a^{*}$ durante a estocagem do suco de umbu co-cristalizado, o que pode ser atribuído à maior estabilidade da clorofila em pH mais elevado, justificando os valores negativos de $a^{*} e$ a coloração verde do produto.

Alexandre (2005) relatou diminuição acentuada da intensidade de vermelho $\left(+a^{*}\right)$ de pitanga em pó armazenada em embalagem laminada aos 60 dias (final do armazenamento). Esse comportamento também foi observado por Aguirre et al. (2003), que relataram o decréscimo na intensidade de vermelho como sendo a alteração mais evidente na cor da acerola em pó armazenada à temperatura ambiente em embalagem aluminizada.

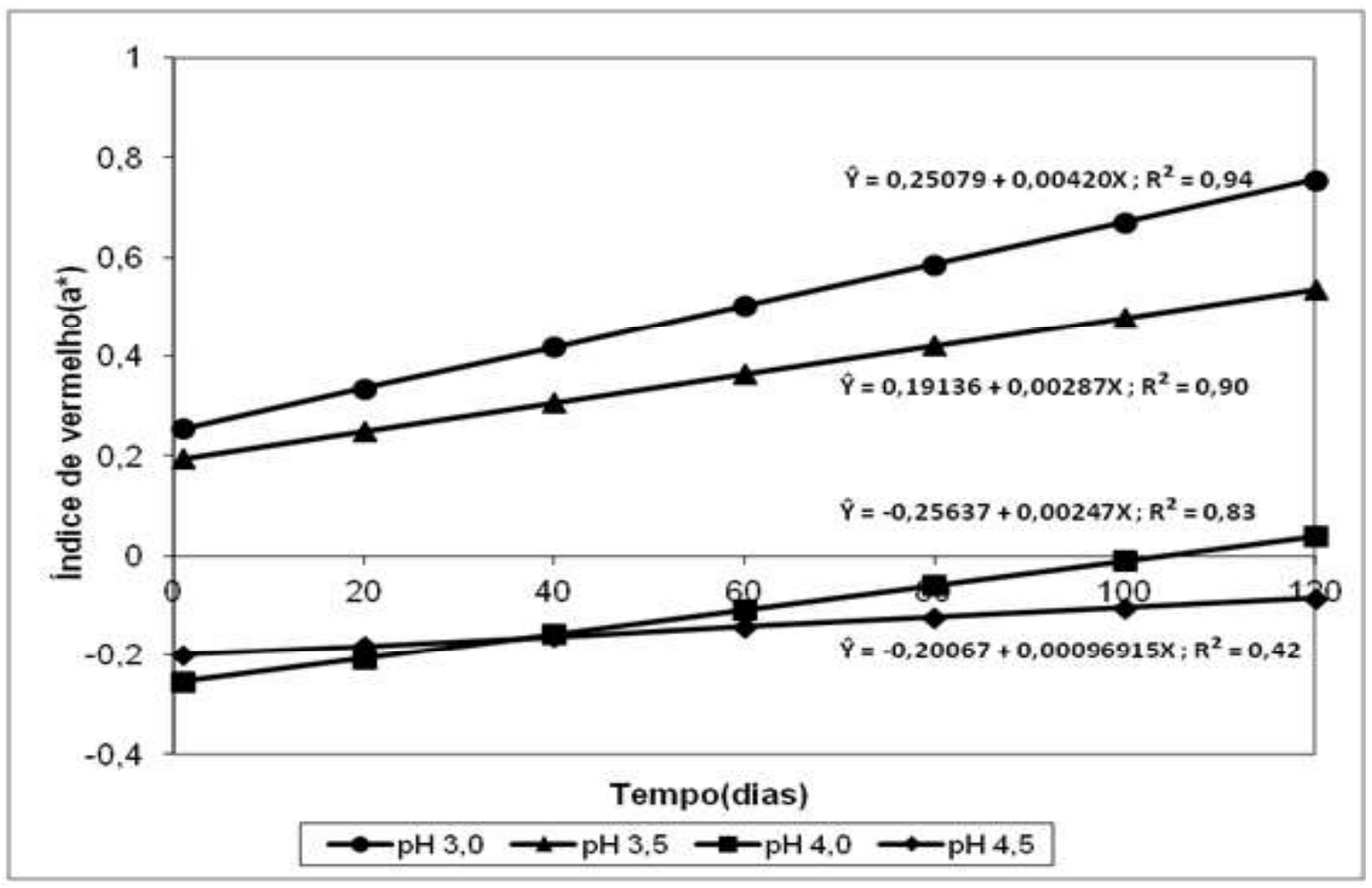

\section{FIGURA 7 - ÍNDICE DE VERMELHO (A*) DO SUCO DE UMBU CO-CRISTALIZADO DURANTE O ARMAZENAMENTO}

De acordo com a análise de variância, houve influência dos tratamentos $(p<0,05)$ e do tempo de estocagem para o parâmetro $b^{*}$. Os resultados foram submetidos à análise de regressão, verificando-se que o modelo de $2^{\circ}$ grau apresentou melhor ajuste para $\mathrm{pH} 3,5 ; 4,0$ e 4,5 e nenhum modelo se ajustou para o $\mathrm{pH} 3,0$. 
A coordenada $b^{*}$ (Figura 8), relacionada ao eixo que varia de azul $\left(-b^{*}\right)$ a amarelo $\left(+b^{*}\right)$, exibiu maiores valores nas menores faixas de $\mathrm{pH}$ do suco de umbu co-cristalizado, principalmente a partir de 40 dias de armazenamento, situando-se na faixa positiva e indicando maior índice de amarelo no produto.

O parâmetro $b^{*}$ mostrou ligeira redução do amarelo, cujo menor valor foi encontrado em maior $\mathrm{pH}$. Entretanto, $\mathrm{o} b^{*}$ situou-se na faixa positiva em todos os tratamentos. Tal fato indica tendência à coloração levemente amarelada, relacionada provavelmente aos carotenoides totais presentes na polpa.

Endo et al. (2007) constataram redução nos valores da intensidade de amarelo de suco de maracujá desidratado em secador por aspersão (spray dryer) e acondicionado em embalagens de polipropileno bi-orientado, metalizado e armazenado a $40^{\circ} \mathrm{C}$. Moura et al. (2007) verificaram, em estudo com maçã-passa armazenada em condições de temperatura controlada, que os valores da intensidade de amarelo permaneceram praticamente os mesmos, não sofrendo alteração com o aumento da temperatura.

A diferença de cor durante o armazenamento indica a eficácia dos tratamentos utilizados, sendo que quanto menor o valor de $\Delta E^{*}$ menor a perda de cor do produto. Vários fatores são responsáveis pelas alterações de cor em produtos alimentícios, incluindo o escurecimento não enzimático e enzimático, e condições ambientais como, $\mathrm{pH}$, acidez, materiais de embalagem, temperatura e tempo, degradação de pigmentos, etc. (COSTA, 2002).

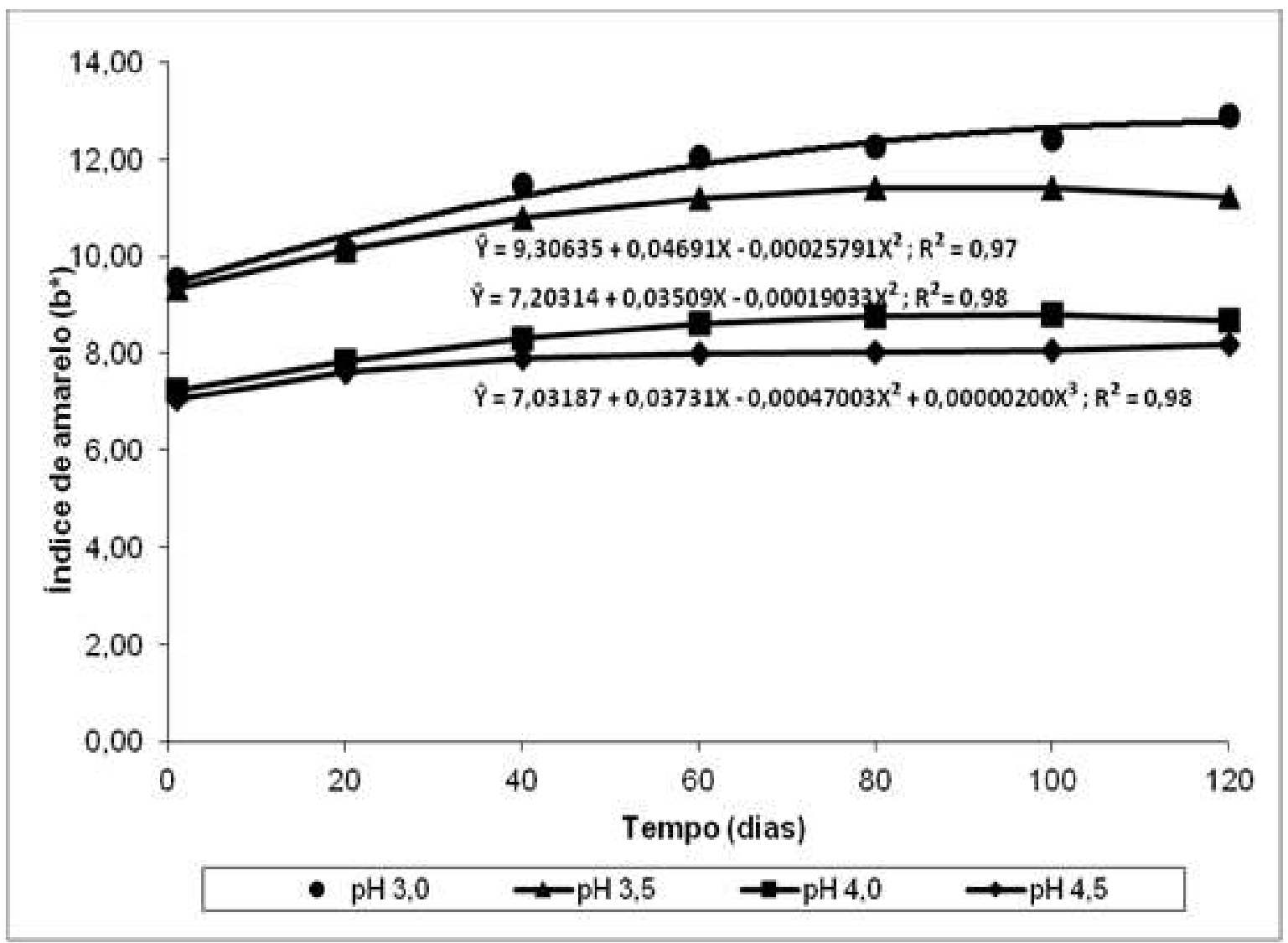

\section{FIGURA 8 - ÍNDICE DE AMARELO (B*) DO SUCO DE UMBU CO-CRISTALIZADO DURANTE O ARMAZENAMENTO}

A análise de variância dos dados obtidos para $\Delta E^{*}$ indicou diferença significativa entre os tratamentos $(p<0,05)$, cujos valores se alteraram devido à ação do tempo e seu comportamento pode ser visualizado na Figura 9. O suco de umbu co-cristalizado produzido com a polpa de 
maior $\mathrm{pH}(4,5)$ apresentou menor valor de $\Delta \mathrm{E}^{*}$, o que significa menor degradação da cor durante o armazenamento. A redução na intensidade da cor pode ser atribuída à oxidação da clorofila, visto que durante o armazenamento esse pigmento pode se oxidar (devido à presença de luz e oxigênio), provocando alterações da cor e redução da qualidade do produto. Já o produto elaborado em menor $\mathrm{pH}(3,0)$ resultou em maior valor de $\Delta E^{*}$, ou seja, maior alteração da cor . Os valores de $\Delta E^{*}$ mostram a variação total entre as amostras em relação ao padrão, no caso o tempo zero, correspondente ao início da estocagem. A partir de 40 dias foi observada maior diferença de cor no tratamento com menor $\mathrm{pH}$.

Talens et al. (2002), desidratando kiwis a $30^{\circ} \mathrm{C}$ em solução de sacarose a 35, 45, 55 e 65 ${ }^{\circ}$ Brix, constataram valores de $\Delta \mathrm{E}^{*}$ que variaram de 11 a 18 , aproximadamente. Martim (2006) relatou valores de $\Delta E^{*}$ de 1,53 a 1,97 para manga desidratada osmoticamente após secagem convectiva. Malheiros (2007) observou aumento progressivo da diferença total de cor durante a armazenagem de erva-mate, similar para as embalagens de papel e laminada.

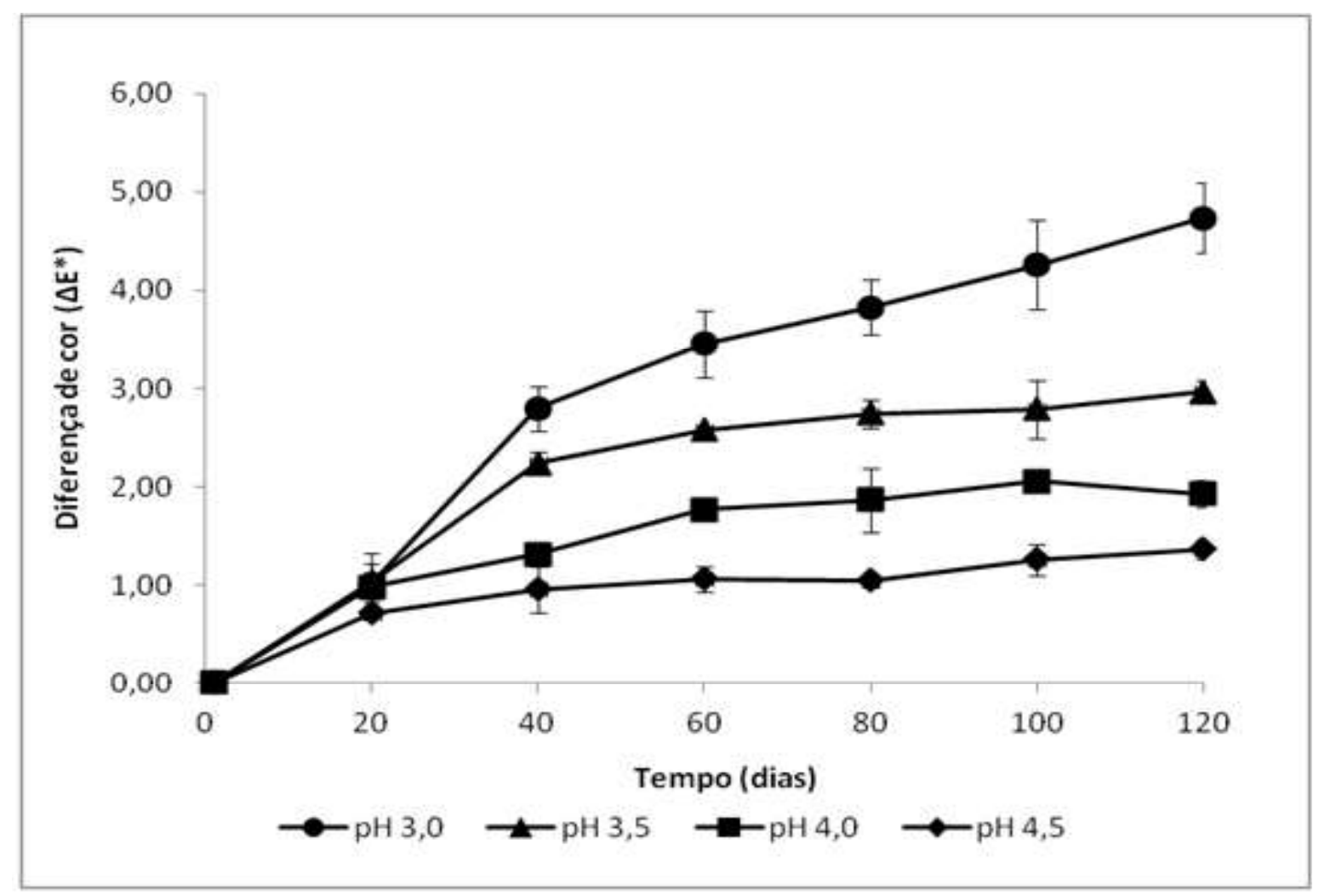

\section{FIGURA 9 - DIFERENÇA DE COR DO SUCO DE UMBU CO-CRISTALIZADO DURANTE O ARMAZENAMENTO}

\section{CONCLUSÃO}

$\mathrm{O} \mathrm{pH}$ da polpa influenciou a atividade de água, o pH, os sólidos solúveis totais, a umidade e a higroscopicidade do suco de umbu co-cristalizado.

O suco co-cristalizado produzido com polpa de menor $\mathrm{pH}$ apresentou menor atividade de água e $\mathrm{pH}$. A polpa com maior $\mathrm{pH}$ resultou em produto com maior conteúdo de sólidos solúveis totais e menor absorção de água e umidade.

$\mathrm{O}$ pH da polpa não exerceu influência sobre a solubilidade e stickiness, resultando em produto com alta solubilidade e baixa pegajosidade.

$\mathrm{O}$ suco co-cristalizado obtido em $\mathrm{pH} 4,5$ apresentou menor diferença de cor durante a estocagem. 


\section{ABSTRACT \\ PHYSICOCHEMICAL CHARACTERISTICS AND STABILITY OF UMBU JUICE BY CO-CRYSTALLIZED WITH SUCROSE}

In the present work, encapsulation of umbu pulp by co-crystallization with sucrose was evaluated by determining the effect of added pulp pH on the physicochemical characteristics of the juice co-crystallized and their stability during storage. The co-crystallized juice showed high solubility and low stickiness standing in the range in which they are most food powders. It was found that, in general way, the umbu juice co-crystallized showed physicochemical characteristics that confer good stability to the product.

KEY-WORDS: CO-CRYSTALLIZATION; UMBU PULP; WATER ACTIVITY.

\section{REFERÊNCIAS}

1 ABADIO, F.D.B. et al. Physical properties of powdered pineapple (Ananás comosus) juice-effect of malt dextrin concentration and atomization speed. Journal of Food Engineering, Essex, v.64, n.3, p.285-287. 2004.

2 Agência Nacional de Vigilância Sanitária (ANVISA). Compêndio da legislação brasileira de aditivos alimentares. 2011, 163 p. Disponível em:< http://portal.anvisa.gov.br/wps/wcm/connect/a6809d8047457a1c86c0d63fbc4c6735/ Compendio_marco_2011.pdf?MOD=AJPERES>. Acesso em: 06 jul. 2013.

3 AGUIRRE, J.M. et al. Desidratação de acerola. In: FITO, P.; MULET, A.;

4 CHIRALT, A.; ANDRÉS, A. Deshidratación de alimentos y propiedades relacionadas. Valencia: UPV, 2003. p.133-138.

5 ALEXANDRE, H.V. Secagem da polpa de pitanga e armazenamento do pó. 2005. 108 f. Dissertação (Mestrado em Engenharia Agrícola), Universidade Federal de Campina Grande, Campina Grande, 2005.

6 ALMEIDA, L.C. Indução de cristalinidade durante o congelamento de soluções modelo com açúcares de frutos com adição de álcoois para reduzir a higroscopicidade dos correspondentes pós-liofilizados. 1995. $87 \mathrm{f}$. Dissertação (Mestrado em Ciência dos Alimentos), Universidade Federal de Lavras, Lavras, 1995.

7 ARAÚJO, J.M.A. Química de alimentos: teoria e prática. 3 ed. Viçosa: UFV, 2004. 478 p.

8 ASTOLFI-FILHO, Z.; SOUZA, A.C.; REIPERT, E.; TELIS, V. Encapsulação de suco de maracujá por co-cristalização com sacarose: cinética de cristalização e propriedades físicas. Ciência e Tecnologia de Alimentos, Campinas, v.25, n. 4, p.795-801, 2005

9 ASTOLFI-FILHO, Z. Encapsulação de sucos de frutas por co-cristalização com sacarose. 2003. 89 f. Dissertação (Mestrado em Engenharia e Ciência de Alimentos), Universidade Estadual Paulista, São José do Rio Preto, 2003.

10 AWAD, A.; CHEN, A. A new generation of sucrose products made by co-crystallization. Food Techonology, v. 47, n.1, p.146-148, 1993.

11 BARBOSA, S.J. Qualidade de suco em pó de mistura de frutas obtido por spray drying. 2010. 122 f. Dissertação (Mestrado em Produção Vegetal), Universidade Estadual de Montes Claros, Janaúba, 2010.

12 BARBOSA, S.J.; FONSECA, K.S.; NORTE, A.R.; CANO-CHAUCA, M.; STRINGHETA, P.C. Análises em suco de açaí obtido por co-cristalização. In: FÓRUM DE ENSINO, PESQUISA, EXTENSÃO E GESTÃO, 3., 2009. Montes Claros. Anais... Montes Claros: UNIMONTES, 2009. Disponível em: www.fepeg.unimontes.br Acesso em: 08. jan. 2013.

13 BASTOS, D.da S.; SOARES, D.M.B.G.; ARAÚJO, K.G. de L.; VERRUMA BERNARDI, M.R. Drying of "Tommy Atkins" mango pulp using foam mat drying. Brazilian Journal Food Technology, v.8, n.4, p.283-290, 2005.

14 BERISTAIN, C.I.; MENDOZA, R.E.; GARCIA, H.S.; VASQUEZ, A. Co crystallization of Jamaica (Hibiscus sabdarifa L.) granules. Lebensmittel-Wissenschaft und-Technolgie, v.27, n.4, p.347-349, 1994.

15 BHANDARI, B.R.; HARTEL, R.W. Phase transitions during food powder production and powder stability. In: ONWULTAT, C. (Ed.). Encapsulated and powdered foods. Boca Raton: Taylor \& Francis, 2005. p. 261-292.

16 BHANDARI, B.R.; DATTA, N.; D'ARCY, B.R.; RINTOUL, G.B. Co-crystallization of honey with sucrose. LebensmittelWissenschaft und-Technologie, v.31, n. 2, p.138-142, 1998

17 CANO-CHAUCA, M.; STRINGHETA, P.C.; RAMOS, A.M. CAL-VIDAL. Effect of the carriers on the microstructure of mango powder obtained by spray-drying and its functional characterization. Innovite Food Science and Emerging Technologies, v.6, p.420-428, 2005. 
18 CANO-CHAUCA, M. Avaliação dos parâmetros de qualidade envolvidos na desidratação da banana (Musa spp.) nanica (AAA). 2000. 74 f. Dissertação (Mestrado em Ciência dos Alimentos), Universidade Federal de Viçosa, Viçosa, 2000.

19 CAVALCANTI MATA, M.E.R.M.; DUARTE, M.E.M.; ALSEMO, G.C.S.; RODRIGUES, E.; GUEDES, M.A.; CAVALCANTI, A.S.R. de R.M.; OLIVEIRA, C.C.A. Obtenção de graviola em pó pelo processo de liofilização. Revista Brasileira de Produtos Agroindustriais, Campina Grande, Especial, v.7, n.2, p.165-172, 2005.

20 CHEFTEL, J.C.; CHEFTEL, H. Introducion a la bioquímica e tecnologia de los alimentos. Zaragoza (España): Acribia, 1980. 403 p.

21 CHEN, W. Z.; Hoseney, R. N. Development of an objective method for dough stickiness. Lebensmittel-Wissenschaft und -Technologie, v.28, p. 467-473, 1995.

22 CHEN, A.C.; VEIGA, M.F.; RIZZUTO, A.B. Co-crystallization: an encapsulation process. Food Technology, v.42, n.11, p.87-90, 1988.

23 CHERIEGATE, A.P.S.C. Análise microestrutural da polpa de amora-preta (Rubbus spp.) co-cristalizada por sacarose. 2012. 93 f. Dissertação (Mestrado em Engenharia de Alimentos), Universidade Federal do Paraná, Curitiba, 2012.

24 COSTA, J.M.C.; FELIPE, E.M.F.; MAIA, G.A.; BRASIL, I.M.; HERNANDEZ, F.F.H. Comparação dos parâmetros físicoquímicos e químicos de pós alimentícios obtidos de resíduos de abacaxi. Revista Ciência Agronômica, v. 38, p.228232, 2007.

25 COSTA, B.S. Influência da temperatura nas alterações de cor no suco de laranja (Citrus Sinensis cv.), determinada através do modelamento cinético. 2002. 105 f. Dissertação (Mestrado em Ciência e Tecnologia de Alimentos), Universidade Federal Rural do Rio de Janeiro, Seropédica, 2002.

26 DANTAS, S.C. de M. Desidratação de polpas de frutas pelo método foam-mat. 2010. 100 f. Dissertação (Mestrado em Engenharia Química), Universidade Federal do Rio Grande do Norte, Natal, 2010.

27 DELADINO, L.; ANBINDER, P.S.; NAVARRO, A.S.; MARTINO, M.N. Co-crystallization of yerba mate extract (IIlex paraguariensis) and mineral salts within sucrose matrix. Journal of Food Engineering, v.80, p.573-580, 2007.

28 ENDO, E.; BORGES, V.S.; DAIUTO, R.E.; CEREDA, P.M.; AMORIM, E. Avaliação da vida-de-prateleira do suco de maracujá (Passiflora edullis f. flavicarpa) desidratado. Ciência e Tecnologia de Alimentos, v.2, p.1-10, 2007.

29 EASTMAN, J.E.; MOORE, C.O. Cold water soluble granular starch for gelled food composition. U.S. Patent 4465702,1984

30 FERREIRA, D.F. O uso do sistema Sas e do Sisvar nas análises estatística: curso de matemática e estatística. 2000. 78 f. Dissertação (Mestrado em Genética e Melhoramento), Universidade Federal de Lavras, Lavras, 2000.

31 FERREIRA, J.C.; CAVALCANTI-MATA, M.E.R.M.; BRAGA, M.E.D. Cinética de congelamento de polpa de umbu a duas temperaturas criogênicas In: CONGRESO LATINOAMERICANA Y DEL CARIBE DE INGENIERIA AGRÍCOLA, 2000. Irapuato. Anais... Irapuato: SLCIA, 2000.

32 INSTITUTO ADOLFO LUTZ. Métodos físico-químicos para análise de alimentos. São Paulo, 2008. (Ed. Digital).

33 KHA, T.C.; NGUYEN, M.H.; ROACH, P.D. Effects of spray drying conditions on the physicochemical and antioxidant properties of the Gac (Momordica cochinchinensis) fruit aril powder. Journal of Food Engineering, Essex, v.98, p.385-392, 2010.

34 LANGDON, T.T. Preventing of browning in fresh prepared potatoes without the use of sulfiting agents. Food Technology, v.41, n.5, p.64-67, 1987.

35 LIMA, L.F.N. do.; ARAÚJO, J.E.V.; ESPÍNDOLA, A.C.M. de. Umbu (Spondias tuberosa Arr. Câm.). Jaboticabal: Funep, 2000. 29 p.

36 MALHEIROS, G.C. Estudo da alteração da cor e degradação da clorofila durante armazenagem de erva-mate tipo chimarrão. 2007. 103 f. Dissertação (Mestrado em Ciência e Tecnologia dos Alimentos), Universidade Federal de Santa Maria, Santa Maria, 2007

37 MARTIM, N.S.P.P. Estudo das características de processamento da manga (Mangifera indica L.) variedade Tommy Atkins desidratada. 2006. 76 f. Dissertação (Mestrado em Tecnologia de Alimentos), Universidade Federal do Paraná, Curitiba, 2006.

38 MATTIETTO, R.A. Estudo tecnológico de um néctar misto de cajá (Spondias lutea L.) e umbu (Spondias tuberosa, Arruda Câmara). 2005. 299 f. Tese (Doutorado em Tecnologia de Alimentos), Universidade Estadual de Campinas, Campinas, 2005

39 MOREIRA, G.E.G. Obtenção e caracterização de extrato microencapsulado de resíduo agroindustrial de acerola. 2007. 86 f. Dissertação (Mestrado em Engenharia Química), Universidade Federal do Rio Grande do Norte, Natal, 2007. 
40 MOURA, S.C.S.R.; BERBARI, S.A.; GERMER, S.P.M.; ALMEIDA, M.E.M.; FEFIM, D.A. Determinação da vida-deprateleira de maçã-passa por testes acelerados. Ciência e Tecnologia de Alimentos, v.27, p.787-792, 2007.

41 NORI, M.A. Ingredientes e aditivos microencapsulados na indústria de alimentos. Engenharia de Alimentos, v. 1, n. 6, p. 33-34, 1996.

42 OLIVEIRA, E. A. Efeitos da pasteurização térmica sobre as características químicas, físico-químicas, sensoriais e reológicas da polpa de umbu (Spondias tuberosa Arr. Câmara). 2006. 55 f. Dissertação (Mestrado em Ciência e Tecnologia de Alimentos), Universidade Federal Rural do Rio de Janeiro, Seropédica, 2006.

43 ORDÓÑEZ, J.A. et al. Tecnologia de alimentos. Porto Alegre: Artmed, 2005. 294 p.

44 OZOGLU, H.; BAYINDIRH, A. Inhibition of enzymic browning in cloudy apple juice with selected antibrowning agents. Food Control, v.13, p.213-221, 2002

45 QUEK, S.Y.; CHOK, N.K.; SWEDLUND, P. The physicochemical properties of spray-dried watermelon powder. Chemical Engineering and Processing, Lausanne, v.46, n.5, p.386-392, 2007.

46 RAMOS, A. M.; QUINTERO, A.C.F.; FARAONI, A.S.; SOARES, N.F.F.; PEREIRA, J.A.M. Efeito do tipo de embalagem e do tempo de armazenamento na qualidade físico-química e microbiológica de abacaxi desidratado. Alimentos e Nutrição, v.19, p.259-269, 2008.

47 SANTOS, I.P.; FONSECA, K.S.; NORTE, A.R.; CANO-CHAUCA, M.; BARBOSA, S.J. Avaliação de propriedades físicas em suco de maracujá em pó obtido por co-cristalização. In: FÓRUM DE ENSINO, PESQUISA, EXTENSÃO E GESTÃO, 3., 2009. Montes Claros. Anais... Montes Claros: UNIMONTES, 2009. Disponível em: www.fepeg.unimontes.br Acesso em: 08. jan. 2013.

48 SHAHIDI, F.; HAN, X.Q. Encapsulation of food ingredients. Critical Reviews in Food Science and Nutrition, v.33, n.6, p.501-547, 1993

49 SHOEFS, B. Chlorophyll and carotenoid analysis in food products. Properties of the pigments and methods of analysis. Trends in Food Science \& Technology, v.13, p.361-371, 2002.

50 SILVA, F.J.; FONSECA, K.S.; NORTE, A.R.; SOUZA, V.B. de; CANO-CHAUCA, M.; STRINGHETA, P.C. Análises de absorção de água em co-cristalizados de suco de açaí. In: FÓRUM DE ENSINO, PESQUISA, EXTENSÃO E GESTÃO, 3., 2009. Montes Claros. Anais... Montes Claros: UNIMONTES, 2009. Disponível em: www.fepeg.unimontes.br Acesso em: 08. jan. 2013.

51 SOARES, E.C.; OLIVEIRA, G.S.F. de; MAIA, G.A.; MONTEIRO, J.C.S.; SILVA Jr., A.; SOUZA FILHO, M. de. Desidratação da polpa de acerola (Malpighia emarginata D.C.) pelo processo foam-mat. Ciência e Tecnologia de Alimentos, Campinas, v.21, n.2, p. 164-170, 2001.

52 SOUSA, A.S.D. et al. Spray dried tomato powder: reconstitution properties and colour. Brazilian Archives of Biology and Technology, Curitiba, v.51, n.4, p.807-817, 2008

53 SOUZA, J.S; ARAÚJO, V.P.U; SOUZA JR, F.E.; ROCHA, S.C.S.; MEDEIROS, M.F.D. Estudo higroscópico e caracterização do mix em pó obtido através do processo de secagem em leito de jorro. In: CONGRESSO BRASILEIRO DE QUÍMICA, 47, 2007, Natal. Anais... Natal: SBQ, v.1, 2007.

54 SPOTO, M.H.F. Desidratação de frutas e hortaliças. Fundamentos de ciência e tecnologia de alimentos. Barueri, SP: Manole, 2006. 612 p.

55 TALENS, P.; MARTÍNEZ-NAVARRETE, N.; FITO, P.; CHIRALT, A. Changes in optical and mechanical properties during osmodehydrofreezing of kiwi fruit. Innovative Food Science \& Emerging Technologies, n.3, p.191-199, 2002.

56 TONON, R.V.; BRABET, C.; HUBINGER, M.D. Influence of process conditions on the physicochemical properties of açai (Euterpe oleraceae Mart.) powder produced by spray drying. Journal of Food Engineering, Essex, v.88, p.411-418, 2008.

57 VON ELBE J.H. Colorantes. In: FENNEMA, O.W. Química de los alimentos. 2. ed. Zaragoza : Wisconsin - Madison, 2000. p.782-799 